\title{
Economical assessment of different HVAC systems for an operating room: Case study for different Turkish climate regions
}

\author{
Gamze Ozyogurtcu, Moghtada Mobedi, Baris Ozerdem* \\ Mechanical Engineering Department, Izmir Institute of Technology, Urla 35430 Izmir, Turkey
}

\section{A R T I C L E I N F O}

\section{Article history:}

Received 11 October 2010

Received in revised form 27 January 2011

Accepted 27 February 2011

\section{Keywords:}

Energy analysis

Energy consumption

Operating room

HVAC system

Life cycle cost

\begin{abstract}
A B S T R A C T
In this study, the annual energy consumptions of four different heating, ventilation and air conditioning (HVAC) systems serving to operation rooms (ORs) located at five different cities (Izmir, Antalya, Istanbul, Ankara and, Erzurum) in Turkey are analyzed. The study is performed for four different HVAC systems: (a) $100 \%$ fresh air system (System I), (b) 100\% fresh air with half air volume rate at night period (System II), (c) $100 \%$ fresh air with half air volume rate at night period and heat recovery unit (System III), (d) $50 \%$ fresh air with half air volume rate at night period and with heat recovery and mixing units (System IV). Life cycle cost (LCC) for 20 years life span is calculated for the considered systems. It is found that System IV considerably reduces energy consumption and it is economically proper for the considered cities. The rate of energy consumption and LCC reductions are greater for the cities with extreme climate condition having relatively low specific humidity ratio. Using System IV instead of System I reduces OR energy consumption by $74 \%$ for the city of Erzurum which has a cold and dry climate.
\end{abstract}

(C) 2011 Elsevier B.V. All rights reserved.

\section{Introduction}

A hospital operating room (OR) as a part of health care facility is one of the most complex indoor spaces in terms of their usage purposes. An OR requires heating, ventilation, and air conditioning (HVAC) for thermal comfort as well as for the removal of infectious airborne particles. The reason for using sterile air in ORs is creating a germ-free environment and keeping this sterile environment condition steady, as much as possible, for all patients and total hospital staff. Application of this type of HVAC systems reduces the risk of infection transmission among patients, surgeons, anesthesiologists, and other medical personnel. This feature makes the sterile HVAC systems to be one of the most effective components to control surgical site infection (SSI) cases. The air at aseptic conditions must be properly filtered and it has to be at appropriate temperature and humidity values with low velocity. This precaution avoids recirculation of microorganisms and therefore, minimizes SSI rates following the operations. Many studies on HVAC of sterile areas in hospitals, in general, were performed and reported in recent years as a result of its importance. The study of Dharan and Pittet [1] has stated that the reduction of particle numbers in an OR decreases the number of SSI cases for orthopedic surgery. Balaras et al. [2] have performed a study for twenty ORs of Hellenic hospitals. They

\footnotetext{
* Corresponding author. Tel.: +90 232 7506783; fax: +90 2327506701 .

E-mail address: barisozerdem@iyte.edu.tr (B. Ozerdem).
}

observed that insufficient indoor air exchange, poor control on indoor thermal conditions, and bad space ergonomics that influence the ventilation system operation are the common problems of hospitals. A computational fluid dynamics (CFD) analysis study conducted by Chow and Yang [3] has simulated the temperature distribution, air flow pattern, and the contaminant dispersion in an OR. The results obtained by this study were also supported by field measurements. Liu et al. [4] have concluded that particle concentration surrounding the patient is highly related to the relative position of the source and layout of the OR. A three dimensional analysis by Ho Son et al. [5] for thermal comfort and contaminant removal in an OR has stated that the closer the supply grills to the center of the OR, the better the performance is. Rui et al. [6] performed a study on biological contaminant control strategies under different ventilation models in hospital ORs. They focused on the airborne transmission of bacteria in two ORs during two surgeries. They found that improving air flow pattern can reduce particle deposition on critical surface, but its effect is less evident by increasing the air change rate in a certain amount, and bacteria colony deposition would increase, if air velocity increases beyond a certain velocity.

First attempt on biologically clean room concept and the creation of related standards and guidelines was conducted by NASA [7]. Later, due to well-known effects of HVAC systems on SSI rates, other organizations in the United States, Germany, and Australia have developed various standards and guidelines for HVAC design parameters in ORs [8]. According to these documents, main param- 
eters which should be under control in an OR are temperature, relative humidity, particle and microorganism count, air velocity and distribution, pressurization, total and outdoor air changes. The ranges of temperature and relative humidity parameters mentioned in these standards and guidelines are $18-26^{\circ} \mathrm{C}$ and $30-60 \%$, respectively.

Sterile HVAC systems for ORs consume significant part of the total energy used in a health care facility. In other words, the operating energy cost of sterile HVAC systems share considerable portion of the total energy bill of health care facility. The energy can be saved if proper HVAC systems are installed in these facilities. Energy conservation systems can reduce energy consumption; however the comfort and sterile conditions must not be sacrificed. A study conducted by Yau [9] has strongly recommended that, the application of heat recovery unit in a sterile HVAC system of an OR using in a tropical climate achieves significant energy savings. Yao and $\mathrm{Ng}[10]$ compared energy savings and fungus growth control in a tropical OR by using heat recovery devices. The HVAC system was redesigned with energy recovery wheel, desiccant dehumidifier and heat pipe heat exchanger to achieve energy saving. They used TRNSYS simulation program and found that the desiccant dehumidifier system and energy recovery wheel integrated system is less favorable for its increased capital cost of equipment and prolonged payback period, while double heat pipe heat exchanger system excelled in both the energy savings and economical aspects.

The above mentioned literature survey shows that two groups of studies are performed on HVAC systems of ORs in hospitals, in general. The first group investigates the effects of HVAC systems on infection risk in an OR. They measure HVAC design parameters such as temperature, fresh air rate, and number of microorganisms in an OR and focus on inappropriate cases. The standards on HVAC systems of ORs are revised based on these studies in order to reduce infection risk. The second group investigates the energy consumption of HVAC systems for ORs. As it was mentioned before, HVAC systems of ORs consume significant energy. Different systems are suggested by HVAC designers and HVAC manufacturing companies in order to reduce energy consumption. However; it should be kept in mind that the energy reduction rate depends on climate conditions.

In the present study, firstly, HVAC parameters of an OR are described to provide a background for reader to understand the function of HVAC system equipment used in ORs. Then, four different HVAC systems used for ORs are analyzed and their annual energy consumptions for different climate conditions are compared based on the performed simulation. The energy analysis of the considered HVAC systems is performed for identical ORs located in five different cities in Turkey as shown in Fig. 1. Energy consumption

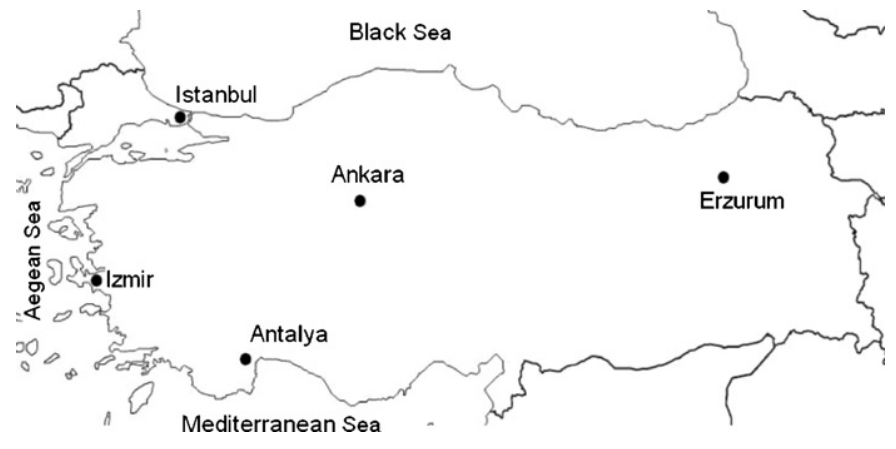

Fig. 1. The location of five cities in Turkey.

analysis is conducted for systems which operate with $2400 \mathrm{~m}^{3} / \mathrm{h}$ of air. Depending on outdoor temperature and relative humidity, sensible heat loads for heating or cooling, latent heat loads for adding or removing of moisture are calculated on an hour base. The variation of annually consumed energy is shown via diagrams. The analyzed HVAC systems are; constant air volume rate system with $100 \%$ fresh air (System I), 100\% fresh air system with half air volume rate at offperiods (System II), 100\% fresh air system with half air volume rate at off period and with a heat recovery unit (System III), and finally $50 \%$ fresh air system with half air volume rate at off-period, and with a heat recovery and a mixing units (System IV). In addition to the annual energy analysis, a net present value (NPV) method is used to determine life cycle cost (LLC) of considered HVAC systems for identical ORs in the five cities.

\section{HVAC design parameters for an operating room}

Number of particles and type of microorganisms, pressure difference between OR and its neighboring spaces, supply air velocity, and air distribution in OR should be seriously taken into consideration during the design of HVAC system of an OR, in addition to the comfort parameters as temperature, relative humidity, and fresh air rate. The comparison of these parameters recommended by different standards and guidelines for an OR has been performed and reported in the literature $[8,11]$. Table 1 illustrates the recommended values of temperature, relative humidity, and air distribution by different standards and guidelines for ORs.

The temperature of an OR has an important effect on thermal comfort of both surgery team and patient. When the health of patient is more important than thermal comfort, the OR temperature must be specified according to the type of operation. For determination of OR temperature, the effects of microorganism

Table 1

Recommended temperature, relative humidity values for ORs.

\begin{tabular}{|c|c|c|c|c|}
\hline Standard/Guideline & OR Classification & Temperature & Relative Humidity & Air Distribution \\
\hline A & - & $20-24^{\circ} \mathrm{C}$ & $30-60 \%$ & Laminar \\
\hline B & - & $20-23^{\circ} \mathrm{C}$ & - & Laminar \\
\hline \multirow[t]{2}{*}{ C } & Class 1 & $19-26^{\circ} \mathrm{C}$ & $30-60 \%$ & Laminar/turbulent \\
\hline & Class II & & & \\
\hline $\mathrm{D}$ & $\mathrm{N} / \mathrm{A}$ & $18-24^{\circ} \mathrm{C}$ & $\mathrm{N} / \mathrm{A}$ & Laminar \\
\hline $\mathrm{E}$ & $\mathrm{N} / \mathrm{A}$ & $18-24^{\circ} \mathrm{C}$ & $30-50 \%$ & Laminar \\
\hline \multirow[t]{3}{*}{$\mathrm{F}$} & Class 1 & $19-24$ & $45-60 \%$ & III \\
\hline & Class II & $19-24^{\circ} \mathrm{C}$ & & $\mathrm{N} / \mathrm{A}$ \\
\hline & Cesarean & $22-26^{\circ} \mathrm{C}$ & & $\mathrm{N} / \mathrm{A}$ \\
\hline G & $\mathrm{N} / \mathrm{A}$ & $\mathrm{N} / \mathrm{A}$ & $30-60 \%$ & $\mathrm{~N} / \mathrm{A}$ \\
\hline $\mathrm{H}$ & $\mathrm{N} / \mathrm{A}$ & $\mathrm{N} / \mathrm{A}$ & $30-60 \%$ & $\mathrm{~N} / \mathrm{A}$ \\
\hline I & General orthopedic & $16-24^{\circ} \mathrm{C}$ & $40-70 \%$ & Laminar \\
\hline \multirow[t]{2}{*}{$\mathrm{J}$} & Option 1 & $18-24^{\circ} \mathrm{C}$ & $50-55 \%$ & Laminar \\
\hline & Option 2 & $18-24^{\circ} \mathrm{C}$ & $50-55 \%$ & Laminar/turbulent \\
\hline
\end{tabular}

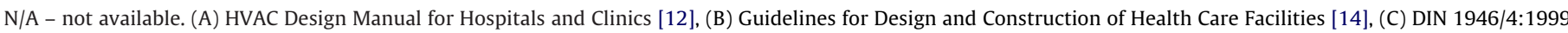

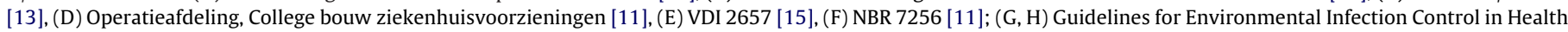
Care Facilities [11], (I) Private Hospital Guidelines [16], (J) Infection Control Guidelines [17]. 

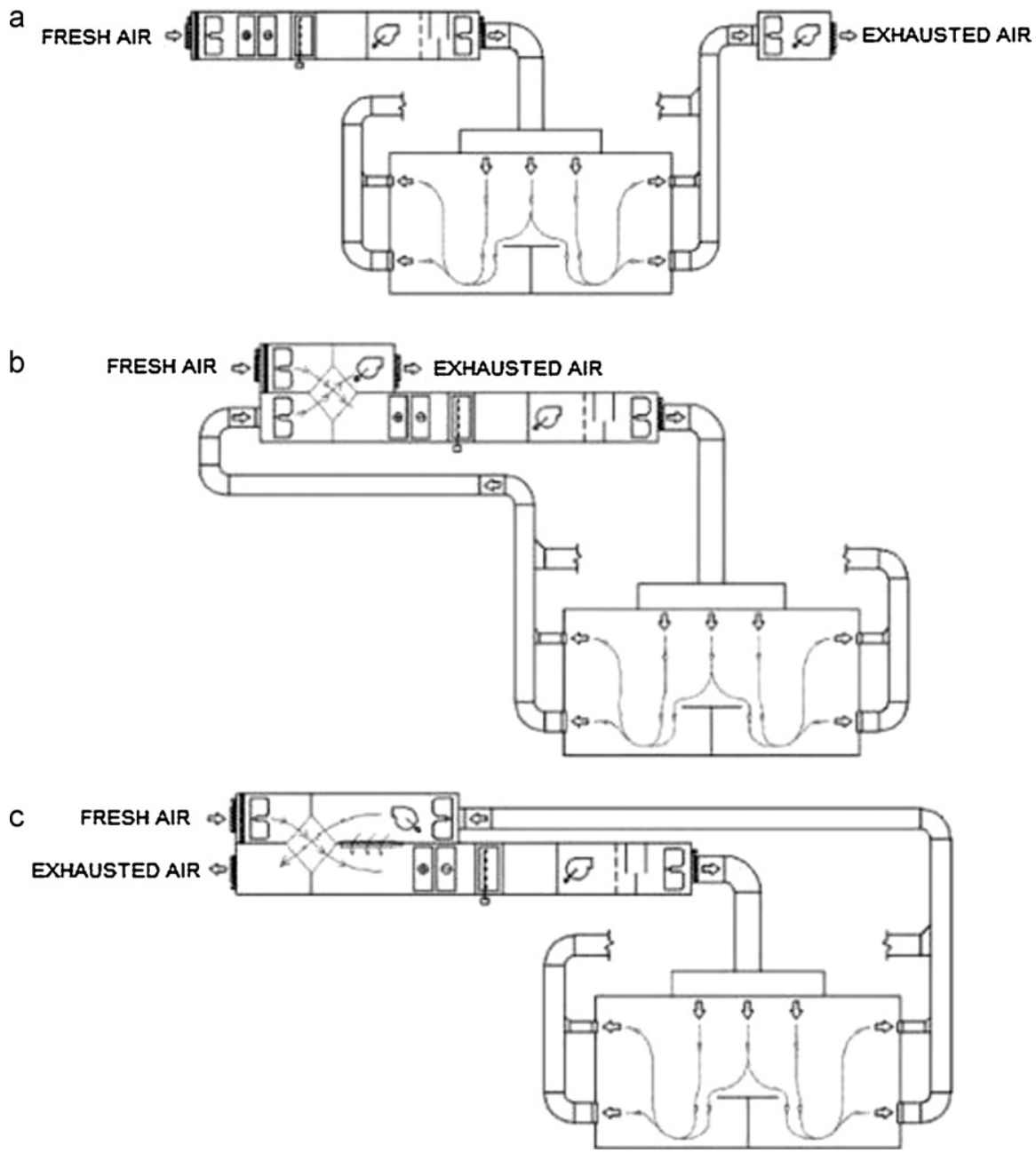

Fig. 2. Schematic views of the studied HVAC systems, (a) Systems I and II, (b) System III, and (c) System IV.

growth, and the immunity system of patient should also be taken into account [12]. Table 1 shows that some of the standards and guidelines classify the ORs according to the type of the surgical operation carried out in the room [8,11-17]. Hence, the type of operation performed in an OR should be known before deciding on the HVAC design parameters. A temperature range between 18 and $24^{\circ} \mathrm{C}$ is recommended by the most of the references but Private Hospital Guideline of Western Australia (PHG) recommends a lower temperature as $16^{\circ} \mathrm{C}$ [16]. The relative humidity level must not affect the thermal comfort of the patient and staff, negatively. It should not cause the microbial growth as well. Generally a wide range of the relative humidity is recommended from 30 to $60 \%$. however a narrow range relative humidity range as $50-55 \%$ is proposed by Infection Control Guidelines of Queensland Australia (ICG) [17].

Laminar flow air supply is recommended by the most reviewed standards and guidelines, but Deutsches Institut für Normung (DIN) and ICG also allow the use of mixing air distribution for ORs under relatively lower sterile conditions [13]. A low air velocity is preferred in ORs. Therefore, the range of supply air velocity for laminar system in an OR is specified by some of the standards such as Verein Deutsche Ingenieure (VDI) between 0.24 and $0.30 \mathrm{~m} / \mathrm{s}$ [15].

Based on the brief information explained above on HVAC design parameters of an OR, it can be concluded that the design of HVAC system of an OR depends on the employed standard. Hence, the design of HVAC systems applied in different countries may differ.
The widely applied HVAC standard for ORs in Turkey is DIN 1946/4 standard [13]. Some HVAC designers in Turkey prefer to use 100\% fresh air systems to prevent any risk for air born infection. Others use mixing units in air handling unit (AHU) since it is allowed by DIN 1946/4. The standard permits mixing of 50\% of fresh air with exhaust air, as well. The standard also allows the use of heat recovery unit. That is why HVAC systems with heat recovery units for OR applications also exist in Turkey.

\section{Simulated HVAC systems}

ORs are generally placed at the center of building to minimize their heat loss and heat gain. For an OR, the HVAC system should operate $24 \mathrm{~h}$ a day. The system should provide filtered and conditioned air even during the off period of the OR. During the off-period, the temperature of the OR should not be high in order to prevent the risk of microorganism growth.

Fig. 2 shows the schematic view of considered HVAC systems for the energy analysis in this study. Since heat gain, heat loss, and heat generation in ORs are not highly changed, it was assumed that air with $15.8^{\circ} \mathrm{C}$ dry bulb temperature and 55\% relative humidity is supplied to OR throughout the year to maintain OR temperature and relative humidity at $18{ }^{\circ} \mathrm{C}$ and $50 \%$, respectively. The positive pressure of air in OR is provided by creating a difference between supply and exhaust air flow rates. For the all considered systems, the air flow rate of supply AHU is assumed to be fixed at $2400 \mathrm{~m}^{3} / \mathrm{h}$, 
while exhaust unit (EU) operates with a constant air volume rate of $2200 \mathrm{~m}^{3} / \mathrm{h}$. The systems operate with the above mentioned air flow rates during $24 \mathrm{~h}$ a day throughout the year. Fig. 2(a) represents Systems I and II. The air conditioning of OR is performed by a supply AHU and an EU. However, both supply AHU and EU of System II operate with half air flow rate during the off-period of OR (i.e. at nights). Hence the air flow rates of System II during offperiod are 1200 and $1100 \mathrm{~m}^{3} / \mathrm{h}$ for supply AHU and EU, respectively. Double speed electrical motors or electrical motors equipped with frequency convertor are used to regulate the flow rates of supply AHU and EU.

Fig. 2(b) shows the schematic view of System III. The operating condition of System III is identical with System II. Thus, the supply temperature and relative humidity ratio are $15.8^{\circ} \mathrm{C}$ and $55 \%$, respectively. AHU and EU of System III also provide half air flow rate during off-period of OR. However, a heat recovery unit is located between AHU and EU to provide heat transfer between exhaust and supply air. During the winter, outdoor air supplied to OR is preheated by recovered heat of exhaust air. Heat recovering unit also reduces the temperature of the outdoor air during summer period before entering to cooling coil.

Fig. 2(c) shows System IV, schematically. The operating condition of System IV is identical with Systems II and III. The heat recovery, used in System III, is also present in System IV. However, a mixing unit is installed to supply AHU and EU of System IV. The outdoor air is mixed with exhaust air with a mixing ratio as $50 \%$ and then, it is supplied to OR after conditioning. DIN 1946/4 allows mixing of fresh air with exhaust air in a HVAC system of an OR. It should be mentioned that a steam humidifier is widely used in HVAC systems of ORs, and the air heating process is performed by using only a heating coil in an AHU.

\section{Determination of thermal loads and energy consumption}

As it was mentioned before, it is assumed that the supply air temperature and relative humidity are constant throughout the year as $15.8^{\circ} \mathrm{C}$ and $55 \%$, respectively. Some part of the consumed energy by HVAC system is used to keep OR temperature at the desired value. The remained is used to regulate humidity level as well. That is why, the sensible and latent heat values are calculated and presented, separately.

The outdoor temperature and relative humidity data concerning five cities are provided by Turkish State Meteorological Service. An hourly base calculation was used to determine thermal loads in this study. The relative humidity ratio measured on sites was converted to the specific humidity ratio by using thermodynamic relations [18]. The total thermal load is calculated by summation of the absolute values of sensible and latent heat loads. The following relations are used to determine sensible, latent and total heat loads of the ORs [18].

$$
\begin{aligned}
& \dot{Q}_{\text {sensible }}=\dot{m} C_{p}\left(T_{\text {supply }}-T_{\text {outdoor }}\right) \\
& \dot{Q}_{\text {latent }}=\dot{m}\left((w h)_{\text {supply }}-(w h)_{\text {outdoor }}\right) \\
& \dot{Q}_{\text {total }}=\left|\dot{Q}_{\text {sensible }}\right|+\left|\dot{Q}_{\text {latent }}\right|
\end{aligned}
$$

where $\dot{m}$ and $C_{p}$ are air mass flow rate and specific heat constant, respectively, and $h$ is the specific enthalpy for saturated water. The values of sensible and latent heat loads can be positive or negative. The positive value of sensible heat load shows that the outdoor temperature is less than supply temperature and it indicates that HVAC system operates in heating mode. The negative value of sensible heat load represents the opposite situation. Similarly, positive value of latent heat signifies a greater specific humidity ratio of supply air compared to outdoor air and hence, the system operates in humidification mode. In a similar manner, the nega- tive value of latent heat load refers to a dehumidification process mode.

The efficiency of heat exchanger depends on exhausted and supplied air temperatures. In practice, the efficiency of the heat recovery unit used in HVAC system changes between 40 and $60 \%$. For the sake of simplicity, heat recovery efficiency is assumed as $50 \%$ throughout the year in this study. The specific humidity and temperature of air at the outlet of mixing unit are obtained from thermodynamic relations [18].

\section{Economical assessment method}

LCC method is used to calculate the summation cost of initial, operating and maintenance of a system. The aim of LCC analysis is to choose the most economical approach from a series of alternatives and to achieve the lowest cost of ownership for a long-term period. The LCC approach harmonizes the money and time by combining possession and sustaining costs.

In LCC method, the economic evaluation of systems is based on long term consideration. In order to determine LCC for a system, various approaches exist for the financial viability analysis of investment such as NPV and internal rate of return (IRR). In this study, NPV approach is used for the economical comparison of HVAC system configurations. By using this approach, the cost and benefit of each option are converted into present value (PV) and the highest NPV is chosen as a preferred option among the alternatives. Mathematical expression of NPV value can be given as follows:

$\mathrm{NPV}=\sum_{n=k+1}^{t} \frac{B_{n}}{(1+i)^{n}}-\sum_{n=0}^{k} \frac{C_{n}}{(1+i)^{n}}$

where $B_{n}$ and $C_{n}$ are benefit and cost values corresponding to systems' life span ( $n$ in years), respectively. The annual interest rate is represented by $(i)$. Since there is no any cash inflow in our case, benefit part of Eq. (4) (i.e., $B_{n}$ ) is ignored. So, the second term in the right side of Eq. (4) is taken into consideration for the economical assessment study. The main cost parameters are sale price of the whole HVAC system including installation and start-up, electricity cost for operating the system and, repair and maintenance cost during the life span of system. The considered systems' life span, $(n)$, is assumed as 20 years. Determination of the annual interest rate, $(i)$, is important in the PV calculations. The annual interest rate kept constant in this study as $10 \%$ throughout the systems' life span. The payments determining the whole costs are taken due at the end of the considered period. The salvage value of the HVAC systems is not taken into consideration during the calculations. The lowest cost option is chosen as the most preferred HVAC system for an operating room.

\section{Results and discussion}

\subsection{Comparison of outdoor temperature and humidity of the cities}

Based on the data provided by Turkish State Meteorological Service, the variations of dry bulb temperature and specific humidity of outdoor air throughout 2006 for different cities are drawn and compared with each others. The comparison results for two cities as Antalya having a hot and humid climate and Erzurum having a cold and dry climate are presented in Fig. 3(a) shows the change of outdoor dry bulb temperature for Ankara and Erzurum throughout 2006. Fluctuations in the diagrams are observed due to the temperature difference during night and day. As seen, the outdoor temperature of Antalya does not drop below $0^{\circ} \mathrm{C}$, however low temperatures such as $-30^{\circ} \mathrm{C}$ can be observed for Erzurum in winter. The outdoor temperature of Antalya is generally above compared to Erzurum both in winter and summer periods. 

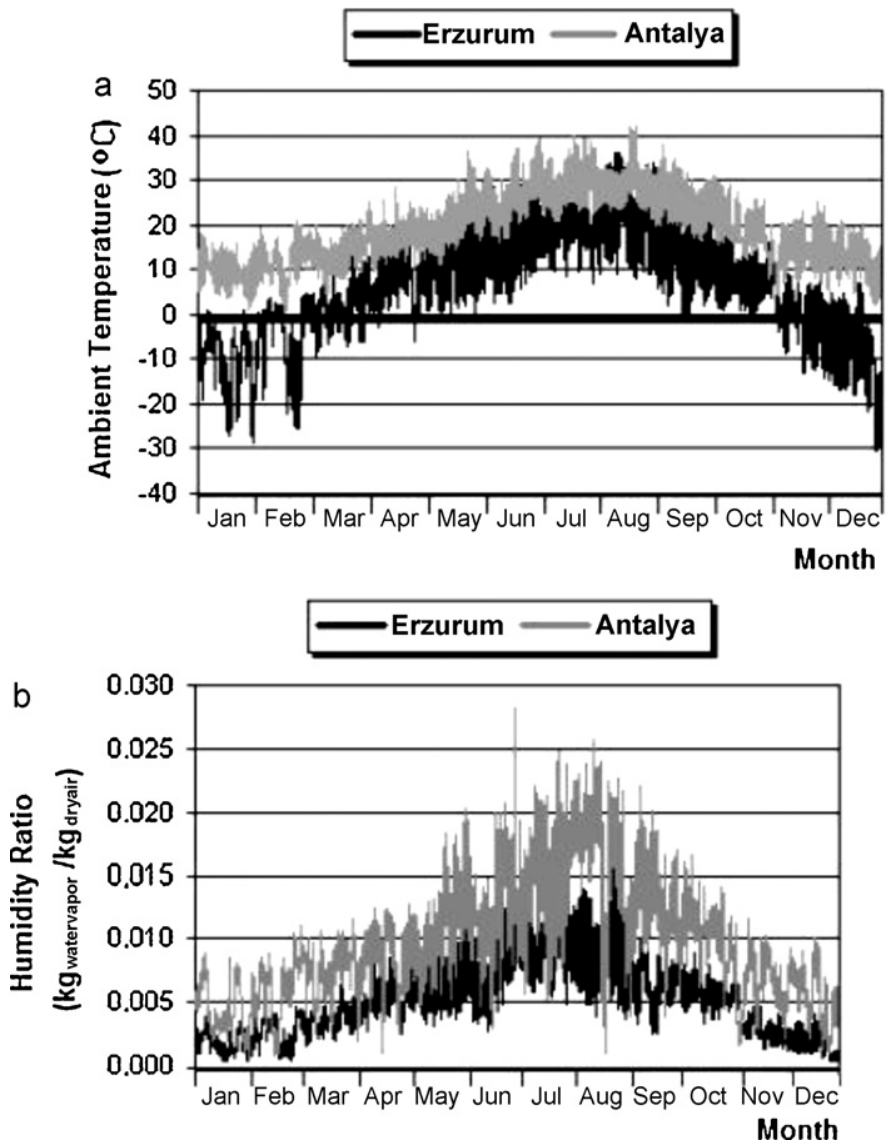

Fig. 3. Outdoor weather conditions for Erzurum and Antalya cities throughout 2006, (a) dry bulb temperature (b) specific humidity.

Fig. 3(b) shows the specific humidity of outdoor air for both cities. As clearly seen, the specific humidity of Antalya is above compared to Erzurum.

\subsection{Comparison of sensible, latent and total loads of HVAC systems}

\subsubsection{Technical results for System I}

The changes of sensible, latent and total loads of System I (i.e., $100 \%$ fresh air for $24 \mathrm{~h}$ ) for Antalya and Erzurum can be seen from Fig. 4. The sensible load of System I in Erzurum is greater than that of Antalya. As it was mentioned before, the positive values of sensible load refers to the heating mode while the negative values signify cooling mode of the system. Fig. 4(b) shows the changes of the latent load of OR. The humidification process is required during the winter season while dehumidification process is required for summer season. Due to the high air humidity of Antalya during summer period, the energy consumed for dehumidification in Antalya is greater than Erzurum. The total thermal load of the OR throughout the year is shown in Fig. 4(c). The total thermal load is the summation of sensible and latent loads. The energy consumption for the System I in Erzurum is greater than Antalya during winter period. However, a reverse trend is observed for summer period. The sensible, latent and total loads of the System I for five cities (Ankara, Antalya, Izmir, Erzurum, and Istanbul) are compared in Fig. 5. Erzurum with $80.2 \mathrm{MWh}$ has maximum sensible load, while Istanbul with $44.0 \mathrm{MWh}$ has the minimum sensible load. The latent load of Ankara with $37.8 \mathrm{MWh}$ is minimum, while Antalya with $68.6 \mathrm{MWh}$ has the maximum latent load. Fig. 5 shows that Erzurum with $123.8 \mathrm{MWh}$ and Ankara with 95.5 MWh has maximum and minimum total energy consump-
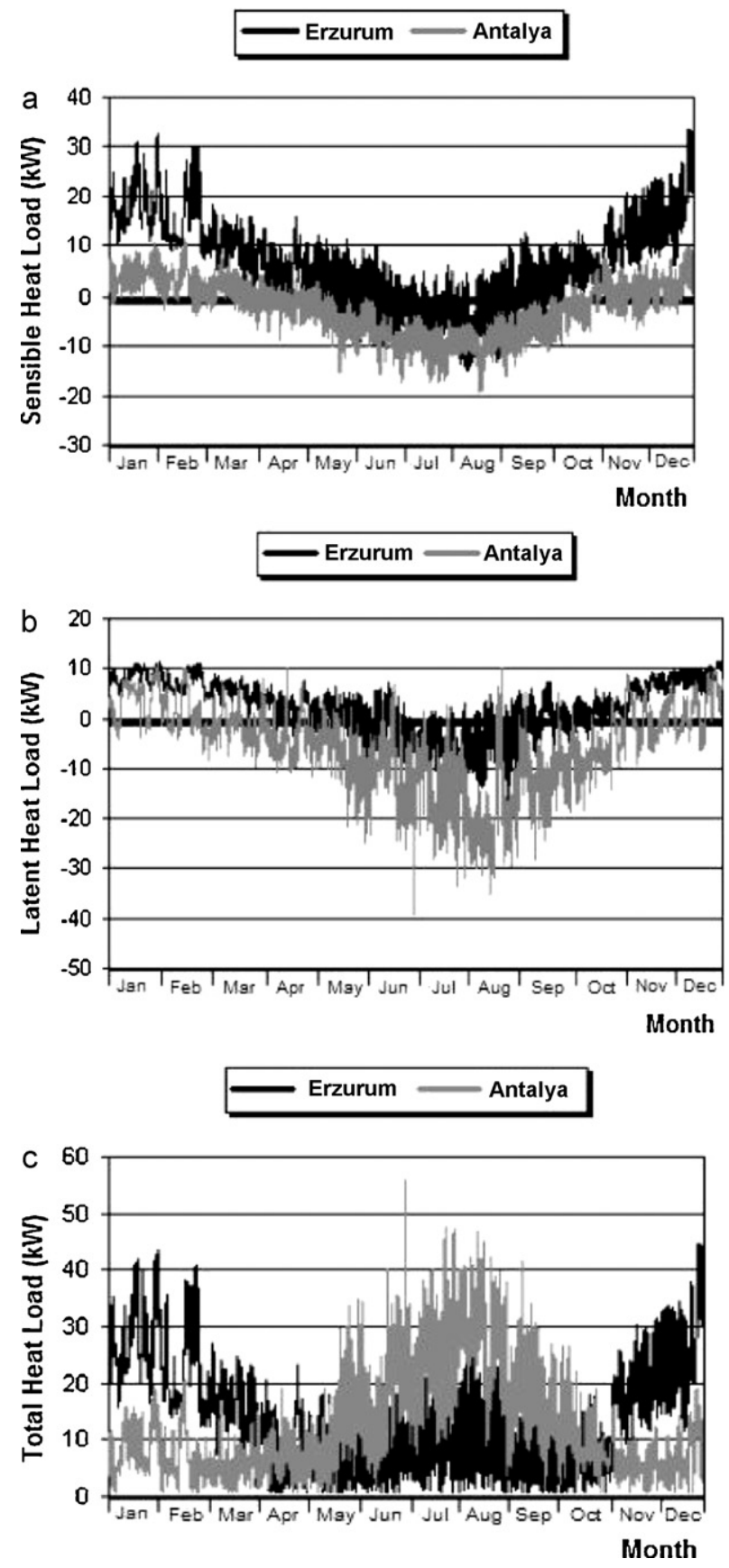

Fig. 4. Changes of energy requirements for an OR in which System I is used for Erzurum and Antalya cities, (a) sensible, (b) latent, (c) total load.

tion (i.e. total thermal load) for air conditioning of the considered OR.

\subsubsection{Technical results for System II}

Fig. 6 shows the sensible, latent, and total energy consumption of the System II for AHU operates with 50\% fresh air during the off-period (i.e. at nights) for the five considered cities. The consumed energy is considerably decreased when Figs. 5 and 6 are compared. Erzurum with 58.8 MWh has the maximum annual sensible load. Minimum value of sensible load belongs to Istanbul with 34.2 MWh. The maximum latent thermal load for Antalya is 53.3 MWh, and Ankara has the minimum latent with 29.1 MWh. Maximum and minimum annual total energy consumptions belong to Erzurum with $91.8 \mathrm{MWh}$ and Ankara with $72.8 \mathrm{MWh}$, respec- 


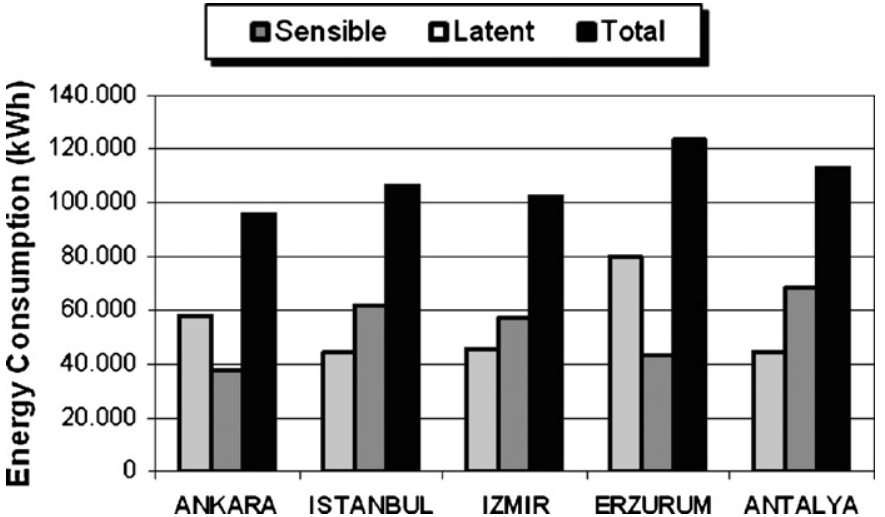

Fig. 5. Comparison of annual energy consumptions of HVAC System I for different cities.

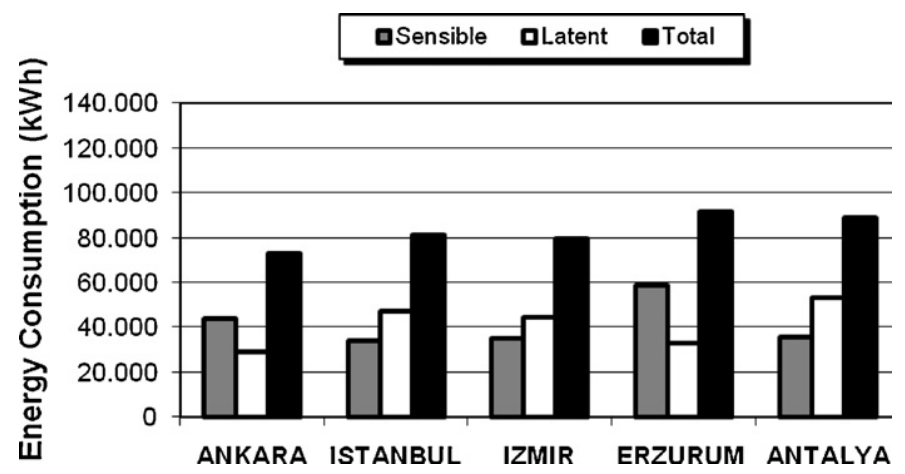

Fig. 6. Comparison of annual energy consumptions of HVAC System II for different cities.

tively. The decrease of air flow rate during the off-period of OR reduces energy consumptions of the HVAC system by $24 \%$ for Ankara, 23\% for Istanbul, 22\% for Izmir, 26\% for Erzurum, and finally $22 \%$ for Antalya.

\subsubsection{Technical results for System III}

Fig. 7 shows the annual energy consumption of System III for the five different cities. The System III operates with half flow rate during the off-period of OR and a heat recovery is used to transfer the heat of exhaust air to the supply air. The comparison of Figs. 6 and 7 shows that the use of heat recovery in the system reduces the consumed sensible heat load. Since no mixing exists between supply and exhaust air, no change was observed on latent heat load. The latent heat load of System III is identical with System II. The reduction of sensible heat load reduces the total energy consumption.

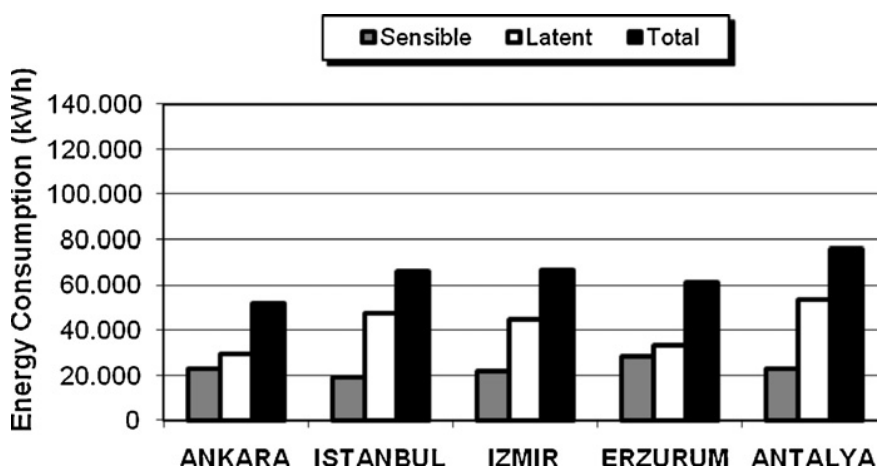

Fig. 7. Comparison of annual energy consumptions of HVAC System III for different cities.

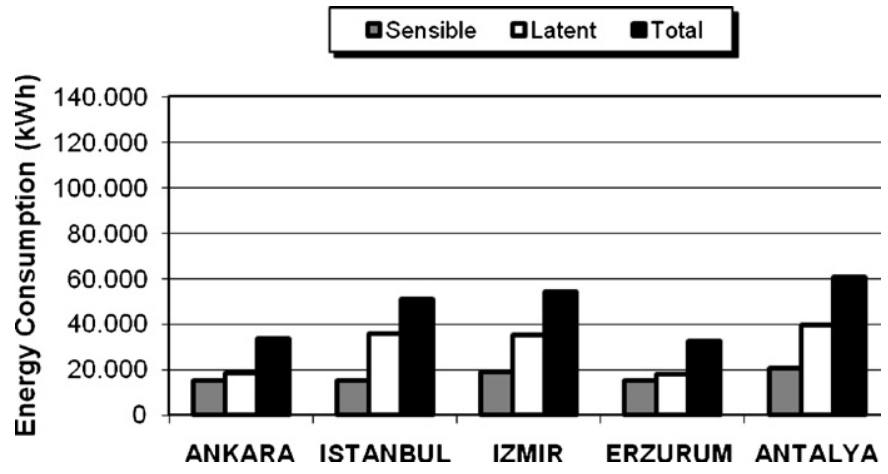

Fig. 8. Comparison of annual energy consumptions of HVAC System IV for different Cities.

Erzurum with 28.3 MWh has maximum sensible heat consumption while the minimum one belongs to Istanbul with 18.7 MWh. The total energy consumption is maximum for Antalya with 76.1 MWh. Ankara with 51.8 MWh has the minimum energy consumption. The interesting point in Fig. 7 is that the total energy consumption for Antalya becomes higher than Erzurum. The heat recovery used between supply AHU and EU highly reduces energy consumption for Erzurum while the recovered heat is not too much for Antalya due to its moderate climate. The use of heat recovery unit reduces the total energy consumption of System by $29 \%$ for Ankara, $19 \%$ for Istanbul, 16\% for Izmir, 33\% for Erzurum, and finally 14\% for Antalya compared with the total energy consumption of System II.

\subsubsection{Technical results for System IV}

As it was mentioned before the AHU of System IV has not only heat recovery unit but also an economizer to use the exhaust air without effecting indoor air quality in the OR. The mixing ratio in the economizer is fixed as 50\%. The amounts of sensible, latent and total energy consumptions for different cities are shown in Fig. 8. The comparison of Figs. 7 and 8 shows that use of economizer in the system reduces both sensible and latent loads. That is why; the latent energy consumption is decreased, as well. The interesting point of Fig. 8 is that, the minimum total energy consumption of System IV belongs to Erzurum, while it had the maximum total energy consumption for Systems I and II. The maximum total energy consumption belongs to Antalya with $60 \mathrm{MWh}$. This shows that for cold regions with relatively low outdoor specific humidity ratio, the use of mixing and heat recovery units is more effective compared to the regions with moderate climates. The use of the System IV for the considered OR reduces the total energy consumption by $35 \%$ for Ankara, $23 \%$ for Istanbul, $19 \%$ for Izmir, $47 \%$ for Erzurum, and finally $21 \%$ for Antalya compared with the total energy consumption of System III.

\subsection{Economical assessment}

Fig. 9 shows the comparison of initial investment of four HVAC systems for five different Turkish cities studied in the present work. The initial investment includes the costs of AHU, EU, chiller, laminar flow unit and other equipment such as pipes and ducts. The cost of labor for assembling was also included. The capacity of the devices determined based on the maximum cooling and heating loads during summer and winter periods. As seen from Fig. 9, the investment cost of HVAC systems for the cities is close to each others, since the most of manufacturers produce devices with limited specified capacities and there is no device with capacity in between. The price of tailored device is too much compared with the cost of regular products. For instance, the manufacturer that provided prices for the equipment of present study offered the same chiller 


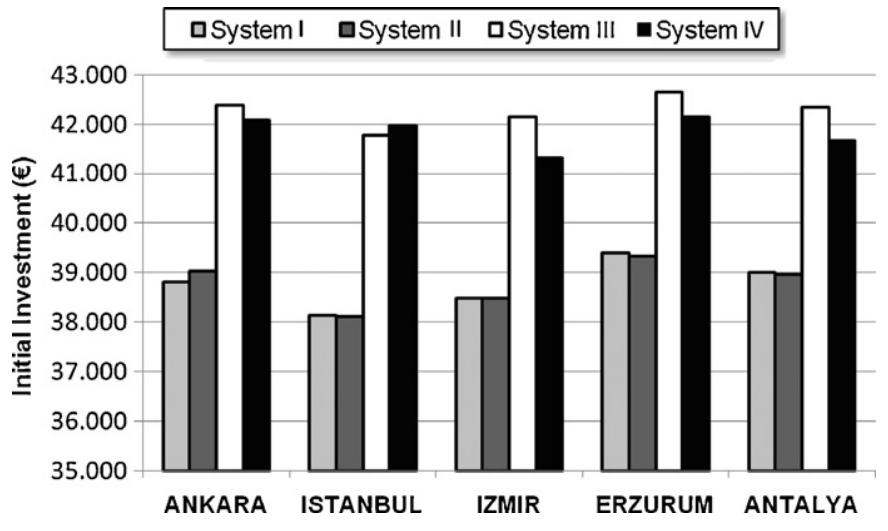

Fig. 9. Comparison of the initial investment of different systems for different cities.

with $21.6 \mathrm{~kW}$ capacity for System I in Izmir and Antalya. But, the maximum cooling load of Izmir is $18.53 \mathrm{~kW}$ which is lower than the cooling load of Antalya with $21.0 \mathrm{~kW}$. That is why, the initial costs of HVAC systems of different cities are close to each others.

Fig. 9 also shows that the initial cost of systems differs with each others. The initial costs of Systems I and II are almost the same, since no new component is added. Due to the heat recovery unit added to System II, a remarkable increase in initial cost of System III is observed. The use of heat recovery unit reduces heating and cooling loads for System III. This causes the capacity of chiller and electrical heater decreases, but high cost of added heat recovery unit still increases total cost of System III, remarkably. That is why, the initial cost of System III increases by nearly $10 \%$ compared to Systems I and II. The use of mixing chamber in System IV does not change the total cost, considerably. A small reduction in total cost of System IV for Ankara, Izmir, Erzurum and, Antalya is observed.

The comparison of LCC of HVAC systems is presented in Fig. 10. The LCC values were obtained by using Eq. (4). They present the total cost of the systems based on PVs. The consumed electricity cost is taken as $0.1115 € / \mathrm{kWh}$ which is the average sale price of electricity in Turkey. In addition, the repair and maintenance cost is assumed as $1876 € /$ year. The system cost for the considered life span includes initial investment, operating and, repair and maintenance. The initial investment is taken for the first year, while the operating and, repair and maintenance costs are taken into account for the next 19 years. As seen from Fig. 10, the minimum LCC for System I belongs to Ankara with 143,651€, whereas Erzurum has the maximum LCC with $170,599 €$, due to the Erzurum's extreme cold climate condition. It should be mentioned that although Izmir, Antalya and, Istanbul have moderate climate conditions compared to Ankara, higher latent loads of the cities with moderate climate

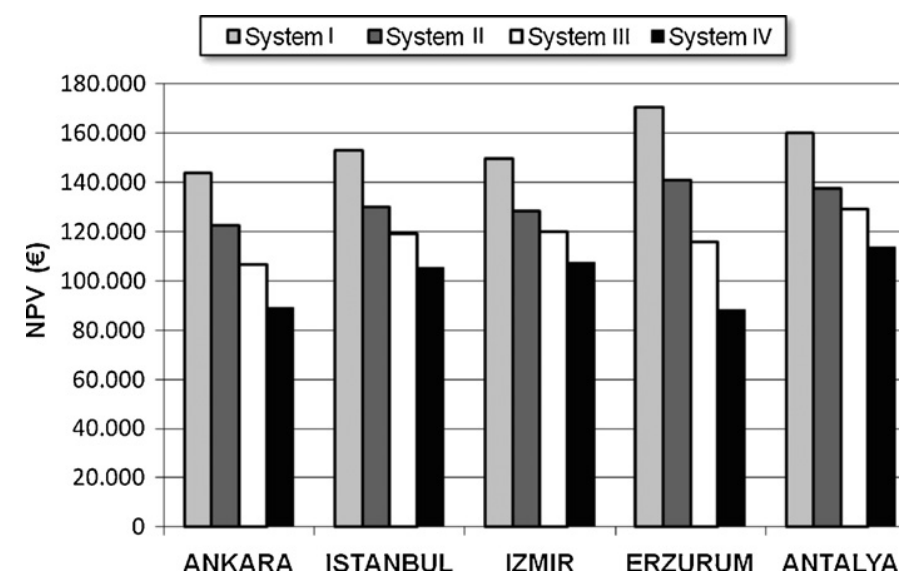

Fig. 10. Comparison of the LCC of different systems for different cities. conditions cause their LCC values to become greater than Ankara. The decrease of air flow rate during off-period of OR (i.e. at nights) reduces the energy consumption and it causes decrease of LCC values for System II for all five cities. For System II, Ankara with 122,653 €and Erzurum with 140,707 €have the minimum and maximum LCC values, respectively. The decrease of air flow rate during off period causes reduction in LCC value of System II for Erzurum by $17.5 \%$. The change of HVAC System from System I to System II for an OR in Erzurum saves 29,892 €for the considered life span. The use of heat recovery unit reduces LCC values for the five cities. However, the rate of reduction for LCC of Erzurum is the highest with $17.9 \%$, when it is compared with the LCC of System II. The effect of heat recovery unit on reduction of LCC values for Izmir, Istanbul and, Antalya is small, since heat recovery unit does not decrease their latent loads. The use of mixing unit reduces LCC values of the five cities further. For System IV, Antalya and Erzurum have the highest and lowest LCC values as $113,633 €$ and $88,241 €$, respectively. The interesting result is that Erzurum has the maximum LCC value for System I whereas the use of System IV changes its order to the minimum. This result shows that the use of heat recovery and mixing units are more effective in the cities with relatively smaller latent loads such as Erzurum and Ankara. For Erzurum, the use of System IV instead of System I reduces LCC value by $48 \%$ and saves $82,358 €$ for the considered time span.

\section{Conclusion}

An analysis on energy consumption of four different HVAC systems for single OR in five different Turkish cities corresponding to different climate conditions was performed to investigate the proper system for each city. Based on the obtained results, the following remarks can be concluded:

- The decrease of air flow rate of System I at nights for an OR reduces energy consumption and LCC, considerably. The decreasing rate of LCC is higher for the regions with extreme climate condition such as the city of Erzurum in Turkey.

- The use of heat recovery and mixing units also reduce the energy consumption and LCC, considerably. The decreasing rate is higher for extreme climate condition compared to moderate climate ones.

- The investment costs of HVAC systems of an OR for different Turkish cities were found close to each others due to regular capacities of HVAC equipment produced in the market. Although, heat recovery unit increases investment cost due to its high price.

- HVAC system with half air flow rate at nights, heat recovery and mixing units has the lowest LCC for the all considered cities. By reducing air flow rate at off-period and using heat recovery and mixing units, energy consumption of System I decreases by $47 \%$, 47\%, 52\%, 65\% and, 74\% for Izmir, Antalya, Istanbul, Ankara and, Erzurum, respectively.

- Using System IV instead of System I reduces LCC by $28 \%, 29 \%$, 31\%, 38\% and, $48 \%$ for Izmir, Antalya, Istanbul, Ankara and, Erzurum, respectively.

- Heat recovery and mixing units are strongly recommended for HVAC systems of ORs when the related standard allows to be applied. They considerably reduce, not only energy consumption of the system, but also LCC value particularly for the cities with smaller latent loads compared to the cities with moderate climate condition having high humidity level. The rate of energy consumption or LCC reduction is strongly depends on the climate conditions. Therefore, annual energy analysis should be performed before the final decision is made on the HVAC system. 
Further studies on different kinds of heat recovery units such as desiccant wheel heat recovery unit for moderate climate condition having high humidity level should be performed, in order to calculate their effects in terms of energy consumption and LCC value of the considered HVAC system.

\section{References}

[1] S. Dharan, D. Pittet, Environmental controls in operating theaters, The Journal of Hospital Infection 51 (2002) 79-84.

[2] C.A. Balaras, E. Dascalaki, A. Gaglia, HVAC and indoor thermal conditions in hospital ORs, Energy and Buildings 39 (2007) 454-470.

[3] T.T. Chow, X.Y. Yang, Ventilation performance in the operating theatre against airborne infection: numerical study on an ultra-clean system, The Journal of Hospital Infection 59 (2005) 138-147.

[4] J. Liu, H. Wang, W. Wen, Numerical simulation on horizontal airflow for airborne particles control in hospital OR, Building and Environment 44 (2009) 2284-2289.

[5] H. Ho Son, L. Rosario, M.M. Rahman, Three dimensional analysis for hospital OR thermal comfort and contaminant removal, Applied Thermal Engineering 29 (2009) 2080-2092.

[6] Z. Rui, G. Tu, J. Ling, Study on biological contaminant control strategies under different ventilation models in hospital operating room, Building and Environment 43 (2008) 793-803.

[7] W. Whyte, Cleanroom Technology: Fundamental of Design Testing and Operation, first ed., John Wiley and Sons Ltd., West Sussex, 2001.
[8] O. Anıl, M. Mobedi, B. Ozerdem, HVAC design parameters of class I rooms in hospitals, 8, in: International Building Technology and Science Symposium, İstanbul, 2008, pp. 324-333.

[9] Y.H. Yau, The use of double heat pipe heat exchanger system for reducing energy consumption of treating ventilation air in an operating theater: a full year energy consumption model simulation, Energy and Buildings 40 (2008) 917-925.

[10] Y.H. Yau, W.K. Ng, A comparison study on energy savings and fungus growth control using heat recovery devices in a modern tropical operating theatre, Energy Conversion and Management 52 (2011) 1850-1860.

[11] M.A. Melhado, J.L.M. Hensen, M. Loomans, L. Forejt, Review of OR ventilation standards, in: 17th International Air-conditioning and Ventilation Conference, Prague, 2006.

[12] American Society of Heating, Refrigerating and Air-Conditioning Engineers, HVAC Design Manual for Hospitals and Clinics, 2003.

[13] Deutsches Institut für Normung, DIN 1946/4 Heating, ventilation and air conditioning systems in Hospitals, 1999.

[14] American Institute of Architects, Guidelines for Design and Construction of Health Care Facilities, 2006.

[15] Verein Deutsche Ingenieure, VDI 2657 Building Services in Hospitals, Heating, Ventilation and Air Conditioning, 2007.

[16] Health Department of Western Australia Facilities \& Assets Branch, Private Hospital Guideline Western Australia, 1998.

[17] Queensland Health Communicable Diseases Unit \& Capital Works Branch, Building and Refurbishment, Infection Control Guidelines, Queensland Australia, 2002.

[18] Y.A. Cengel, M.A. Boles, Thermodynamics: An Engineering Approach, third ed. McGraw-Hill, 1998. 